\title{
INHALT
}

\section{DIE WELTMISSIONSKONFERENZEN}

Edinburg, Juni $1910 \ldots \ldots$. . . . . . . . 7

Jerusalem, März/April 1928 . . . . . . . . . 10

Tambaram (Südindien), Dezember 1938 . . . . . . . . 22

Whitby (Canada), Juli 194? . . . . . . . . . 24

II. DIE WELTKONFERENZEN FUR PRAKTISCHES

CHRISTENTUM

Stockholm, August 1925

Die Allgemeine Einladung . . . . . . . . . . . . . 38

Die Einladung der Europäischen Sektion . . . . . . . 41

Die Botschaft . . . . . . . . . . . . . .44

Oxford, Juli 1937 . . . . . . . . . . . . . 49

III. DIE WELTKONFERENZEN FUR GLAUBEN

UND KIRCHENVERFASSUNG

Lausanne, August 1927 . . . . . . . . . . . . . . . . . . . . . .

Edinburg, August 1937 . . . . . . . . . . . 80

IV. DER WELTBUND FUR FREUNDSCHAFTSARBEIT DER KIRGHEN

Prag, August 1928 . . . . . . . . . . . . . . . . 82

Cambridge, September 1931 . . . . . . . . . 83

Chamby (Schweiz), August 1935 ......... . . 84

V. DER OEKUMENISCHE RAT DER KIRCHEN

Einladungsbrief zur Teilnahme am Oekumenischen Rat . . . 88 Genf, Februar 1946 . . . . . . . . . . . . . . .90 Aufruf an die Kirchen der Welt . . . . . . . . . . . 92 
